4. $\mathrm{i}^{2}:$ in

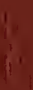

4

Is. 


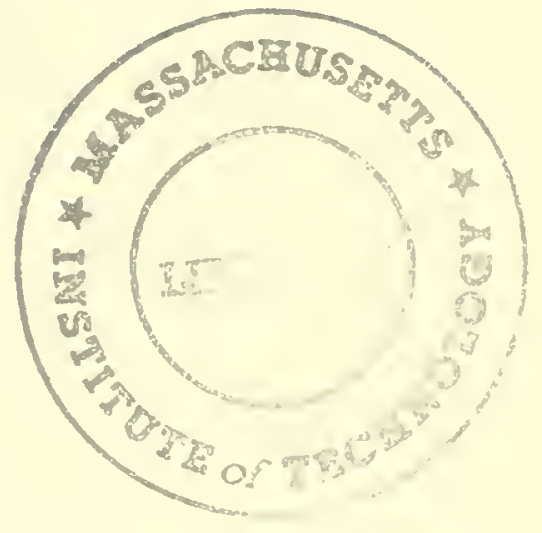






\section{WORKING PAPER \\ ALFRED P. SLOAN SCHOOL OF MANAGEMENT}

Choice over Uncertainty and Ambiguity in Technical Problem Solving

Stephan Schrader*, William M. Riggs* and Robert P. Smith*/+

February, 1993 WP\# 3533-93-BPS

MASSACHUSETTS

INSTITUTE OF TECHNOLOGY

50 MEMOAIAL DRIVE

CAMBRIDGE, MASSACHUSETTS 02139 
<smiles>C1CCC1</smiles> 
Choice over Uncertainty and Ambiguity in Technical Problem Solving

Stephan Schrader*, William M. Riggs* and

Robert P. Smith*/+

February, 1993

WP\# 3533-93-BPS

Forthcoming in:

Journal of Engineering and Technology Management, Vol 10, 1993

* Massachusetts Institute of Technology

Alfred P. Sloan School of Management

50 Memorial Drive

Cambridge, MA 02139

USA

+ Cranfield Institute of Technology

School of Mechanical, Materials and Civil Engineering

Royal Military College of Science

Shrivenham SN6 8LA

England 


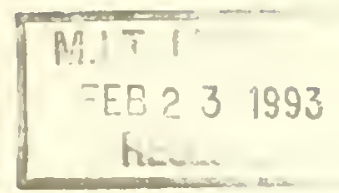




\title{
Choice over Uncertainty and Ambiguity in Technical Problem Solving 1
}

\author{
Stephan Schrader, William M. Riggs and Robert P. Smith
}

\begin{abstract}
Technical problems are solved under uncertainty and ambiguity. Most empirical research in technical problem solving has two characteristics in common: no differentiation between uncertainty and ambiguity is made, and the degree of uncertainty or ambiguity is considered exogenous to the problem-solving process. This paper argues, first, that uncertainty and ambiguity are dissimilar concepts, thereby following ideas proposed by the recent literature. Problem solving under ambiguity involves fundamentally different tasks than problem solving under uncertainty. Consequently, different organizational structures are appropriate and different types of resources needed. Second, it is argued that levels of uncertainty and ambiguity are not exogenously given but rather are determined in the problemframing process. In this process, problem solvers select explicitly or implicitly specific levels of uncertainty and ambiguity. This choice is contingent on context characteristics such as prior problem-solving experiences, organizational context, and available resources. It is proposed that the efficiency of the problem-solving process and the outcome of the process depends on the fit between the levels of uncertainty and ambiguity chosen and the context characteristics. Implications of the proposed framework for research on communication gatekeepers and on the role of top managers in technical change are discussed.
\end{abstract}

KEYWORDS: Problem solving, problem framing, technology management, uncertainty, ambiguity

\section{INTRODUCTION}

Research on problem solving, especially on technical problem solving, has addressed the effects of ambiguity and/or uncertainty on the problem-solving process (Marples 1961; Sutherland 1977), the interplay between uncertainty/ambiguity and organization structure (Marquis and Straight 1965; Lawrence and Lorsch 1969; Larson and Gobeli 1988), and the need for different communication channels under different uncertainty/ambiguity conditions (Tushman 1978; Tushman and Nadler 1980; Allen 1984). Most empirical work on technical problem solving has two characteristics in common. First, no explicit distinction between uncertainty and ambiguity is made; the two concepts are used as if they were interchangeable although the literature provides several frameworks to

1 We are thankful to Philip Anderson, Eric von Hippel, Andrew King, David Rabkin, Michael Toole, Kentaro Nobeoka, Henry Kon, Shyam Chidamber, Mary Tripsas, and three anonymous reviewers for helpful comments. 
distinguish between them. Second, uncertainty and ambiguity are considered exogenously given variables, variables managers must react to.

In this paper, we argue that uncertainty and ambiguity are dissimilar concepts $^{2}$ and that technical problem solving may involve both uncertainty and ambiguity. Recognizing the difference between uncertainty and ambiguity is important since the two concepts relate to different problem-solving processes, requiring different kinds of organizational support. In addition, we propose that viewing uncertainty and ambiguity as exogenously given variables is a misrepresentation of the problem-solving process. We argue that one core task in problem solving is the choice of the problem's uncertainty and ambiguity levels in the process of problem framing. Thus, levels of uncertainty and ambiguity are not exogenously given, but are the results of explicit or implicit choice. This choice is at least partly contingent on the situational context. We propose that the efficiency of the problem-solving process and the outcome of this process depends on the fit between the uncertainty and ambiguity levels chosen, the resources available, and the organizational context.

Technical problem solving is central to the management of technology and innovation. The notion that uncertainty and ambiguity are selected in the problemframing process affects our understanding of such problem solving. It is important to focus attention on this selection process, since this is the point at which the nature of the subsequent problem-solving process as well as its potential outcome are determined to a great extent.

By viewing uncertainty and ambiguity as exogeneously given, a crucial aspect of the problem solving process is neglected. A notion underlying most current strategies towards technical problem solving is that both the problem and the set of possible solutions are always in flux-thus contradicting the assumption of the objectively correct problem definition. It is more and more taken for granted that any given technical solution is not the "final" solution, but that improvements are always feasible. This requires a continued willingness of problem solvers to question current assumptions and solutions-thereby reintroducing ambiguity and uncertainty into the process.

Individuals and companies vary widely in how they approach apparently similar technical problems, suggesting that there are indeed dimensions of choice in the framing of these problems (Burns and Stalker 1966; Clement 1989). The fact that outcomes also differ greatly implies that framing choices matter.

\section{UNCERTAINTY AND AMBIGUITY}

The concepts of uncertainty and ambiguity have been defined in a number of ways in the organizational literature, depending on the nature of the research question being addressed. In this section we will briefly review these definitions,

2 Similar arguments are made by, for example, March 1978; McCaskey 1982; Einhorn and Hogarth 1986; Martin and Meyerson 1988. 
and then offer definitions which we find appropriate for discussing problem solving in a technological environment.

Traditionally, both information theory and decision theory have viewed uncertainty as a characteristic of situations where the set of possible future outcomes is identified, but where the related probability distributions are unknown, or at best known subjectively (e.g. Luce and Raiffa 1957; Garner 1962; Owen 1982). (Decision theory also defines the concept of risk as a special case of uncertainty; that is, uncertainty with known probabilities, e.g. Shubik 1982. We argue below that in technical problem solving no situations with objectively known probability distributions exist.)

Organization researchers have built on the above definitions, broadening them to fit the organizational context. Galbraith (1973) defines uncertainty as the difference between the information an organization has and the information it needs. This coincides with early definitions of uncertainty provided by researchers on the psychology of problem solving (e.g. Miller and Frick 1949), as derived from the mathematical theory of communication (Shannon and Weaver 1949). In both lines of research, uncertainty is viewed as stemming from a paucity of information.

In an effort to develop specific measures of uncertainty in the context of organization research, Duncan (1972) operationalizes uncertainty as containing three components:

"(1) the lack of information regarding environmental factors associated with a given decision-making situation, (2) not knowing the outcome of a specific decision in terms of how much the organization would lose if the decision were incorrect, and (3) inability to assign probabilities with any degree of confidence with regard to how environmental factors are going to affect the success or failure of the decision unit in performing its function."

The first two of these components focus on the lack of information, in a manner similar to the broad definition of Galbraith (1973). The third component is similar to the narrower definitions such as proposed by information theorists and decision theorists, but emphasizes that participants assign probabilities to outcomes subjectively, leaving doubt as to the accuracy of these probabilities.

A common thread running through these definitions is that in each case uncertainty relates to a lack of information. Consequently, if problem solvers wish to reduce uncertainty, they must gather information about variables that are known to them.

Several authors, however, argue that models of decision making under uncertainty frequently do not describe adequately real world decision making (e.g. Conrath 1967; March 1978; McCaskey 1982; Daft and Lengel 1986; Einhorn and Hogarth 1986; Gimpl 1986; Martin and Meyerson 1988). They propose that often possible future outcomes are not identified or well defined, and that there may be conflict with regard to what these will or should be. These authors maintain that decision making and problem solving are often carried out under conditions of ambiguity, rather than uncertainty, where ambiguity is defined as lack of clarity 
regarding the relevant variables and their functional relationships (Martin and Meyerson 1988, p. 112). ${ }^{3}$

\section{Mental Models and the Distinction Between Uncertainty and Ambiguity}

What is different between a situation that is characterized by a lack of information (uncertainty) and a situation characterized by a lack of clarity (ambiguity)? We propose that the differences in the mental models used by problem solvers can help to distinguish more clearly between ambiguity and uncertainty and to determine organizational consequences of this distinction. The availability and precision of the mental models is greater under uncertainty than under ambiguity. This difference has considerable ramifications for how problems are solved and for how to manage the problem-solving process.

Mental models guide individuals' behaviors, especially their problemsolving behavior (Mintzberg 1976; Brief and Downey 1983; Simon 1987; Clement 1989). 4 "In effect, managers (like everyone else) use their information to build mental models of their world, which are implicit synthesized apprehensions of how their organizations and environments function. Then, whenever an action is contemplated, the manager can simulate the outcome using his implicit model" (Mintzberg 1976, p. 54). Mental models determine what is relevant for understanding a specific phenomenon or for solving a problem. A well-defined mental model implicitly predetermines the relevant solution space for a problem (Clement 1989).

When facing a problem, problem solvers might feel that they know what to do, what specific information to look for, and what results to strive for. In this case, the problem solvers have mental models available to them that they consider adequate for the problem. This model demarcates the boundaries of the problem and identifies the specific tasks necessary to solve the problem.

Alternatively, problem solvers might think they do not yet have a "good grip" on the problem. This would imply an inability to decide on the problem scope, to define the tasks involved, to discriminate relevant from irrelevant inputs, or to identify desired outcomes. In other words, problem solvers perceive no adequate model of the problem structure to be available. They must find or create an appropriate model as part of the problem-solving process.

The first situation characterizes problem solving under uncertainty. The uncertainty is created by the problem solver not yet knowing the precise characteristics of the outcome of the problem-solving process. If the outcome were known a priori, this would not be a case of problem solving. But the problem solver has, in his or her view, a sufficiently clear understanding of the problem structure;

3 Ambiguity relates directly to Daft and Lengel's (1986) notion of equivocality, which they define as "...ambiguity, the existence of multiple and conflicting interpretations about an organizational situation."

4 Other terms for the same concepts are frames (Goofman 1974), interpretive schemes (Giddens 1984; Gash and Orlikowski 1991) and cognitive maps (Bougon, Weick and Binkhorst 1977). 
i.e. he or she possesses a mental model that guides the problem-solving process. The problem-solving process involves specifying the precise values of the variables of the mental model. The informational needs are well defined.

The second situation characterizes problem solving under ambiguity. Ambiguity exists because the problem solver is not yet satisfied with his or her understanding of the structure of the problem and consequently of the problemsolving process. The problem solver does not have a mental model available that is considered adequate to guide problem solving behavior. If the problem solver perceives such a lack of understanding, first steps of the problem-solving process will relate to the determination of a mental model to guide problem solving activity.

Two levels of ambiguity can be demarcated. The first level refers to a situation in which the problem solver takes the set of relevant variables as given. However, he or she perceives ambiguity in regard to the relationship between the variables and the problem solving algorithm. The second level refers to a situation in which not only the functional relationships and problem solving algorithms but also the relevant variables are seen as in need of determination. Thus, uncertainty and ambiguity can be distinguished in the following way:

Uncertainty: Characteristic of a situation in which the problem solver considers the structure of the problem (including the set of relevant variables) as given, but is dissatisfied with his or her knowledge of the value of these variables.

Ambiguity level 1: Characteristic of a situation in which the problem solver considers the set of potentially relevant variables as given. The relationships between the variables and the problem solving algorithm are perceived as in need of determination.

Ambiguity level 2: Characteristic of a situation in which the set of relevant variables as well as their functional relationship and the problem solving algorithm are seen as in need of determination. ${ }^{5}$

\section{The Difference Between Uncertainty Reduction and Ambiguity Reduction}

Problem solving is frequently characterized as a process of uncertainty and/or ambiguity reduction (e.g. Sutherland 1977). It follows from the definitions of uncertainty and ambiguity provided above that the processes of uncertainty reduction and ambiguity reduction must be distinct and qualitatively different in structure, content and approach.

Uncertainty reduction is the process of gathering information relevant to the variables defined within one's mental model. The problem solver has a model that he or she considers adequate to the problem. This model corresponds to an integrated

5 The set of assumed relationships between variables reflects the problem solver's understanding of the structure of the problem. The problem-solving algorithm relates to how this understanding is to be used for problem solving. 
conception of all relevant factors and their functional relationships. Problem solving involves gathering information relevant to this model and integrating this information according to the assumed functional relationships.

Reduction of ambiguity is the process by which a model considered to be appropriate to the problem is found or developed. Ambiguity, as we have seen, is the state in which the problem solver feels that he or she does not know what the relevant variables and their functional relationships are. It is lack of clarity in a problem situation. Constructing a model to specify the relevant variables and the relationships between them is a creative process requiring rethinking of inputs, processes, and outputs. Thus, ambiguity reduction is inherently less structured and less predictable than uncertainty reduction.

The difference between these two processes implies that they involve different tasks. In the case of uncertainty reduction the key tasks are information gathering and integration. In the case of ambiguity reduction, the tasks are model building, negotiation, problem framing, evaluating and reframing, and model testing.

\section{THE CHOICE OF UNCERTAINTY AND AMBIGUITY LEVELS}

We suggest that no a priori criterion exists for determining the degrees of uncertainty and ambiguity of a specific problem. This proposition is contrary to most of the discussion of uncertainty and ambiguity found in the literature, where it is assumed that the levels of uncertainty and/or ambiguity in a given situation are exogenously given. We propose that, contrary to this assumption, uncertainty and ambiguity are not exogenous to the problem solver, but rather that the relevant levels of uncertainty and ambiguity are determined in the problem-framing process. In addition, we argue that since uncertainty and ambiguity refer to different attributes of a problem solver's framing of a situation, the two concepts cannot be placed on a single continuum.

\section{Subjective Determination of Uncertainty and Ambiguity}

The proposition that no externally given, ex ante definable levels of uncertainty and ambiguity exist will be developed and illustrated using the prediction of heads or tails in a coin toss. The problem of tossing a coin and predicting the outcome is usually regarded as a problem of known risk, i.e. of a known probability distribution. But is this necessarily the case? The person tossing a coin might assume that heads and tails are equally likely, following the tradition of most textbooks on statistics. Nobody, however, can know this with certainty-at least if one subscribes to a theory of knowledge following the tradition of critical rationalism as laid out by Popper $(1968 ; 1972)$. Another possibility is that the person assumes heads and tails occur in a fixed but still unknown ratio and may decide to use Bayes' theorem to reach a better estimate of this ratio. In this case, the problem solver would frame the problem as one of uncertainty. He has decided on what variables to consider relevant (i.e. occurrences of head and tails in trial tosses) and 
has made assumptions regarding their general functional characteristic (i.e. heads and tails occur at an independently set ratio) and thus can collect information regarding these variables. However, another alternative exists as well: the player may reject the propositions that the game is fair or that the ratio is constant. He could decide to attempt to determine factors that affect the outcome distribution. He therefore might strive to determine variables likely to influence the outcome. In this case, the player creates ambiguity regarding the problem structure. He may investigate whether the coin is bent or has any physical defect which produces a bias. He may experiment to determine whether the way the coin is thrown has an influence on the outcome. Or he may consider the possibility that the coin might sometimes land on its edge, thus introducing another outcome possibility. In other words, the player (or problem solver) must choose the scope of the problem and thereby the levels of uncertainty and ambiguity involved.

Two conclusions can be drawn from this example:

(1) The traditional distinction between risk (known probability distribution) and uncertainty (unknown or subjective probability distribution) is not helpful in the context of problem solving. The problem solver never knows with certainty if an objective probability distribution exists and what the precise characteristics of this distribution are. He can at best estimate those characteristics-in other words, he has to decide on what to consider a useful representation of reality.

(2) The scope of the problem and the range of potential outcomes are selected in the problem-framing process. This conflicts with the traditional view that the levels of uncertainty and ambiguity are objective characteristics of a given problem. As the example shows, the problem solver has control over what elements of the problem to consider uncertain and what as ambiguous. (However, the example also shows that frequently problems are predefined by our conventional understanding. Most of us will have learned in school to see tossing a coin as a problem of known risk-50:50. And in most cases, this assumption serves us well. Some well-trained gamblers, however, might be more careful, either considering the distribution as uncertain or even assuming that the tosser of the coin can influence the outcome. And again, this different approach to framing the problem might serve them well.)

The second conclusion has particular relevance in technological problem solving, since the technical scope and the characteristics to expect of the outcome (for example, which technologies to use in development and what performance to expect of a new product) are not known a priori. The organizational context frequently seems to induce its members to frame problems as problems in uncertainty rather than ambiguity, thereby limiting the possible solutions to the ones that fit within existing mental models (Schon 1967; Henderson and Clark 1990). Conversely, some $R \& D$ environments appear to provide little incentive to reduce ambiguity, thus fostering technical wandering and corresponding missed schedules as well as high development cost (McDonough and Leifer 1986). Thus, it is of central importance to understand and manage the process of choosing the levels of uncertainty and ambiguity in technological development. 
The Uncertainty/Ambiguity Matrix

We suggest that a problem solver decides in the problem-framing process on both the level of ambiguity and the level of uncertainty involved. In other words, ambiguity and uncertainty are not concepts on the same dimension. Ambiguity reduction and uncertainty reduction relate to different aspects of the problem-solving process. Whereas uncertainty reduction refers to the determination of the value of variables, ambiguity reduction relates to the determination of the set of relevant variables and of underlying relationships.

A problem may be framed so that it contains, for example, a high degree of uncertainty and a low degree of ambiguity. But it is also conceivable to frame a problem such that it contains a low degree of uncertainty and a relatively high degree of ambiguity. The following figure 1 illustrates the different uncertainty-ambiguity combinations. (Since it is not possible to have certainty about the variable values without knowing which variables are or might be relevant, the combination of low uncertainty and level 2 ambiguity does not exist.)

The following discussion illustrates how the same problem may be framed using different combinations of uncertainty and ambiguity. For this example it is assumed that a production manager (the problem solver) is faced with the problem of planning the production program for a semiconductor manufacturer. Suppose that over the past year the process for the production of semiconductor chips in this specific plant had an average yield of approximately $50 \%$ (not uncommon for a complex microchip product requiring many precision steps in its manufacture), with weekly values from as low as $40 \%$ to as high as $60 \%$. The production manager can frame his task in many ways, thereby placing it in different positions on the uncertainty-ambiguity matrix.

Case 1: The production manager can choose to regard this yield as an inherent characteristic of the process and he may consider appropriate, for example, a simple production planning rule such as always producing twice as much as needed. In this case, the manager considers all variables necessary for solving the problem to be known and he has a clear understanding of what procedure to apply to perform the task. Thus low ambiguity and low uncertainty prevail in his problem framing. Once the problem is framed in this way, he needs only to apply the chosen algorithm.

Case 2: Alternatively, the production manager may have, in his own view, a sufficiently good understanding of what drives production yield. In other words, he considers the relevant variables (but not their values) to be known and their functional relationship as satisfactorily well understood. However, as long as he does not know the value of these variables, he faces a problem of high uncertainty and low ambiguity. Instead of taking the $50 \%$ average yield as the only relevant information, he may, for example, gather information on the quality of the photoresist from various suppliers, on the technical complexity of the semiconductor chips to be produced, and on who will be running the production line 
FIGURE 1

The Uncertainty-Ambiguity Matrix

UNCERTAINTY REDUCTION

\begin{tabular}{|c|c|c|}
\hline & Uncertainty low & Uncertainty high \\
\hline Ambiguity low & $\begin{array}{l}\text { Model using } \\
\text { - Variables known } \\
\text { - Values known } \\
\text { - Functional relationships } \\
\text { known } \\
\qquad \text { Case } 1\end{array}$ & $\begin{array}{l}\text { Model using } \\
\text { - Variables known } \\
\text { - Values unknown } \\
\text { - Functional relationships } \\
\text { known } \\
\text { Case } 2\end{array}$ \\
\hline $\begin{array}{l}\text { Ambiguity high } \\
\text { Ambiguity level } 1\end{array}$ & $\begin{array}{l}\text { Model building } \\
\text { - Variables known } \\
\text { - Values known } \\
\text { - Functional relationships } \\
\text { unknown } \\
\text { Case } 3\end{array}$ & $\begin{array}{l}\text { Model building } \\
\text { - Variables known } \\
\text { - Values unknown } \\
\text { - Functional relationships } \\
\text { unknown } \\
\text { Case } 4\end{array}$ \\
\hline Ambiguity level 2 & & $\begin{array}{l}\text { - Variables unknown } \\
\text { - Functional relationships } \\
\text { unknown } \\
\text { Case } 5\end{array}$ \\
\hline
\end{tabular}

on specific days, in order to more precisely predict future production yields. All these information gathering activities are to reduce uncertainty, thereby allowing better prediction of the weekly yields, improving his output predictability.

Case 3: A third possibility is that the production manager considers all the relevant variables and their values as known and that he sees his task primarily as one of determining an algorithm for linking them in a meaningful way to reach a sufficiently good production plan. For example, his view could be that yield is influenced, as in case 2, by photoresist quality, chip complexity and operator skill. Contrary to case 2, however, he thinks he has good enough measures of these variables. He sees his task primarily as determining a functional relationship between these variables and yield. In this case problem solving consists of 
investigating these relationships and of finding appropriate algorithms that can be employed to predict future yield and to plan production runs accordingly.

Case 4: Here the production manager thinks he knows sufficiently well which variables are important, but the understanding of the functional relationships between these variables and of the variable values is not considered adequate. In our example, adequate measures of photoresist quality, chip complexity and operator skill must be found in addition to determining the relationship between these variables and output yield.

Case 5: As the final alternative, the production manager may decide that he does not have an adequate understanding of the underlying problem structure, that his task is to identify the relevant variables as well as the functional relationships. In addition to resist quality, chip complexity and operator skill, he might search broadly for other variables influencing yield, considering, for example, room temperature, particulate levels, humidity, or other factors. Because the variables are unknown, their values are also unknown and must be determined. This type of problem solving requires both ambiguity and uncertainty reduction.

As this example shows, several alternatives can exist for framing a problem, each time placing it in a different position on the uncertainty-ambiguity matrix. Ex ante, no inherently right way can be determined. Ex post, it might be possible to determine that one way yielded a more desirable outcome than another.

As implied by the arrows on Figure 1, the position of a problem does not remain fixed on the matrix during the process of problem formulation and solution. Instead, it will move as the problem solution is developed. For example, the problem solver may see a problem as ambiguous, and address it by first formulating a rough model (Einhorn and Hogarth 1986; Clement 1989). He or she may then test this model with a limited data to see if it is helpful. If not, it will be discarded and a new model tried. If so, the model may be refined and tested further via more detailed data gathering. In this process the problem's position on the matrix works its way upward as ambiguity is reduced to a low level by formation of a more and more satisfactory model, and to the left as data are systematically gathered to reduce uncertainty about anticipated outcomes.

Although the position of a problem on the uncertainty-ambiguity matrix is determined in the problem-framing process, this process does not occur unconstrained. Rather, as we will argue in the next section, the choice is contingent on the situational context, especially the available resources and the organizational context. The fit between the chosen levels of uncertainty and ambiguity and the situational context affects both the efficiency of the problem solving process and the characteristics of the outcome.

\section{CONTINGENCY OF THE CHOICE}

Throughout the earlier sections of this article, the argument has been put forward that a task is not characterized ex ante by specific levels of uncertainty and ambiguity, but that problem solvers decide in the problem-solving process on the uncertainty-ambiguity levels. In this section, we propose that this decision is contingent on the problem solver's prior problem solving experiences, on the 
organizational context, and on the available resources. We suggest testable propositions which illustrate how the choice of uncertainty and ambiguity levels affect and are affected by the problem-solving process.

\section{Prior Problem Solving Experiences}

Problem solving behavior is strongly influenced by past experiences. Successful problem solving leads to a reinforcement of the models used and to a reduced likelihood of challenging these models (Schon 1967; Nelson and Winter 1982; Hannan and Freeman 1984). Failure, on the other hand, encourages reconsideration of the models being used (Hedberg 1981; Tushman and Anderson 1986; Anderson and Tushman 1990). To challenge a model used previously for solving an apparently similar problem implies that the problem solver introduces ambiguity into the problem-solving process by questioning existing assumptions about which variables are important and about how they relate to each other.

In the context of investigating organizational learning, Levitt and March (1988) argue in a similar vein that organizational routines change in an incremental manner in response to feedback about how the outcomes of these routines compare to the actors' levels of aspiration. Consequently, prior problem-solving success with problems that are perceived as isomorphic or related in nature will lead to problem framing that involves little ambiguity.

Proposition 1 a: Problems will be framed with low ambiguity if the problem solver has successfully solved apparently isomorphic or related problems previously.

At the same time, prior success reducing uncertainty regarding core variables in an apparently similar problem reconfirms the belief that such uncertainty is reducible, thus favoring a problem understanding that involves uncertainty with respect to the same or similar variables. For example, assume the semiconductor plant production manager in the illustration above had, on a previous job assignment, improved the precision of a production forecasting model by including and measuring worker experience, product complexity and photoresist quality. Given these circumstances, when facing an apparently like problem he will be more inclined to simply reuse the model (i.e. little ambiguity) and to concentrate on determining the variables as precisely as possible (i.e. high uncertainty). In other words, his prior problem solving success will predispose him to seek more detailed values for the variables than if he had not measured them successfully in the past.

Proposition 1b: High uncertainty will be accepted if the problem solver has successfully reduced uncertainty in apparently isomorphic problems previously. 


\section{Organizational Context}

Empirical evidence suggests that the organizational context greatly influences problem perception and problem framing. Burns and Stalker (1966), for example, have described how different organization structures foster or hinder the ability to perceive problems in a new light and to generate fresh solutions. The literature on the management of technology and the literature on organizational change provide evidence for the impact of contingency variables such as organization structure (Marquis and Straight 1965; Allen and Hauptman 1987), rules, norms and work patterns (Nelson and Winter 1982; Levitt and March 1988, Levinthal 1992), and status and political systems (Burns and Stalker 1966) on the ability of organization members to frame problems in new ways. As long as the organizational system is such that it exerts considerable control over the models individuals are willing or able to use, problems are more likely to be framed as uncertain rather than as ambiguous. Such control can be explicit, for example through rules governing the problem-solving process, or it can be implicit through such characteristics as a strong socialization process inducing individuals to perceive and solve problems in a predetermined way. Broadly, it can be argued that an organic organization structure as described by Burns and Stalker exerts less control and thereby induces individuals to frame problems with a relatively high level of ambiguity.

Proposition 2.1: Organizational environments that exert considerable control over their members favor problem framing with little ambiguity.

Such a directional proposition cannot be put forward for the relationship between organizational control and the accepted levels of uncertainty. It can be proposed, however, that problem solvers have less discretion regarding problem framing in environments that exert considerable control over participants or outcomes. For example, in the context of a research contract, the contracting agency might prespecify certain variables. This externally imposed problem definition restricts the researcher's latitude to choose the problem structure. Similarly, one individual's framing choices may also be affected by framing choices of other members of the organization-especially if several persons are assigned to work on the same or on supposedly interdependent problems.

The existence of apparently conflicting and irreconcilable information is frequently at the root of an ambiguous problem framing (Kosnik 1986; Meyerson and Martin 1987). However, organizations have the tendency to prevent such information from disseminating freely. Information filters often inhibit the flow of information that contradicts existing expectations (Henderson and Clark 1990). In addition, even if conflicting information is available within an organization, the structure of the existing information channels may not link the problem solver to this information. For example, an engineer working in one R\&D group might not learn about recent discoveries by another $R \& D$ group that would impact the way she frames her problem. Already Burns and Stalker (1966) provided evidence showing how lateral communication networks foster the communication of information that is 
outside the direct realm of the problem solver's expertise. Consequently, communication networks that provide problem solvers with only a few linkages and that do not link different areas of expertise through horizontal linkages will inhibit individuals from receiving conflicting information and thereby will favor problem solving within the boundaries of accepted models.

Proposition 2.2 a:Communication networks that provide few horizontal communication linkages inhibit the reception by the problem solver of apparently conflicting information. Such a lack of conflicting information will foster problem framing that involves little ambiguity.

The structure of communication networks serves as an indicator for the difficulty of acquiring different types of information (Yates 1989). Some information may be easier to access than other. Problem solvers will tend to concentrate their problem solving efforts on those areas in which information is attainable, as long as they consider the problem's solvability in the problem framing process. If, for example, existing communication networks in an engineering group provide engineers with ready access to specific kinds of information (i.e. computer links to technical databases) they will tend to frame their problems so that the available information can be of help.

Proposition 2.2 b: High uncertainty will be accepted primarily in those areas in which existing communication networks support the acquisition of information.

\section{Resources}

Problem solving requires resources including time, human problem-solving skills, and material resources. These resources have a double nature. On the one hand, they are prerequisite for the problem-framing process and the subsequent processes of uncertainty and ambiguity reduction. On the other hand, they may limit the amount of ambiguity problem solvers are willing and/or able to inject into the problem-solving process, especially if the value of some resources depends on the problem solver's choosing a specific problem-solving approach.

Resources can differ greatly in the extent to which they favor specific problem-solving approaches. Some resources-especially time and money-are by themselves not solution-specific. Other resources, however, lose their value if they are not used in the context of a specific problem-solving approach. These resources we characterize as solution-specific. For example, in the semiconductor process illustration, an analytical instrument for measurement of the quality of the photoresist may be specific to that particular material and not usable for other 
applications. (The distinction between solution-specific and non-solution specific resources is isomorphic with Teece's (1985) notion of specialized and generic assets).

The availability of solution-specific skills and resources impacts both the amount of ambiguity and the degree of uncertainty framed into a problem. A large body of literature on decision making suggests that decision makers tend to prefer solutions that utilize existing assets or continue past investment patterns-even if the resulting outcome is to be suboptimal (i.e. Staw 1976; Fox and Staw 1979; Samuelson and Zeckhauser 1988). Building on this stream of research, the following general tendency can be postulated regarding problem framing.

Proposition 3.1: The availability of solution-specific problem-solving skills and resources biases problem solvers toward framing the problem so that these skills and resources can be employed in the problem-solving process.

The existence of solution-specific skills will hinder most individuals from framing problems with such a degree of ambiguity that their existing skill set might not be applicable. Academic disciplines, for example, provide solution-specific skills which may prevent those trained in these disciplines from considering knowledge acquired by other fields as relevant to their problems or even from questioning the assumptions of their own field (Kuhn, 1962; Latour, 1987). A similar argument holds for the availability of other solution-specific resources. For example, a chemical research laboratory that has invested in a supercomputer will be likely to favor molecular modeling using the computer over considering more extensive laboratory bench experimentation. The availability of specialized resources limits greatly the degree of ambiguity problem solvers are willing to accept. Ways of framing the problem which will lead to solution strategies that do not utilize the available specialized resources are likely to be neglected.

Proposition 3.1 a: The availability of solution-specific problem-solving skills and resources induces problem solvers to restrict the range of acceptable ambiguity.

Uncertainty reduction, on the other hand, frequently requires solutionspecific skills and resources, such as specific measurement instruments. The availability of such resources implies that problem solvers will tend to be familiar with the specific methods of obtaining information and that they will tend to know how to value and use this information based on prior experience. Consequently, they have an incentive to frame problems in such a way that uncertainty can be reduced substantially by use of these resources. Allen (1966), for example, describes a case in which a research team's solution strategy is greatly influenced by the availability of a specific measurement resource, in this case a wind tunnel. 
Proposition 3.1 b: The availability of solution-specific problem-solving skills and resources induces problem solvers to accept greater uncertainty in those areas in which uncertainty can be reduced by applying these skills and resources.

The availability of non-solution-specific resources and skills is a prerequisite for pursuing problem-solving approaches novel to the problem solver. In the absence of sufficient non-solution-specific resources, problem solvers may refrain from framing problems such that a need for ambiguity reduction exists. For example, the above described manager of the semiconductor manufacturing process may accept the historic yield data as a good predictor for future yield data simply because he does not have the time to explore the yield problem further. On the other hand, the provision of unrestricted research funding is often stimulus enough to challenge past convictions. This is, for example, one of the underlying assumptions behind unrestricted grants such as the MacArthur Fellowships in academia. Similar logic underlies the $3 \mathrm{M}$ Corporation's well-known policy of allowing researchers up to $15 \%$ of their time to pursue problems outside their officially assigned research program.

Proposition 3.2: The availability of non-solution specific skills and resources may induce problem solvers to frame a problem as containing reducible ambiguity.

Finally, the personalities of the problem solvers themselves can be viewed as a resource. Empirical evidence exists suggesting that individuals differ greatly in their personal disposition to accept ambiguity in the problem-solving process (e.g. Kirton 1976; Foxall and Payne 1989). Kirton states, "...it has been observed that among managers advocating particular changes are some men who 'fail to see possibilities outside the accepted pattern' while others are marked as 'men of ideas,' who fail to exhibit a knack for getting their notions implemented" (Kirton 1976, p. 628). Such differences in the personal predisposition of problem solvers will also influence their choices of uncertainty and ambiguity levels.

Proposition 3.3: Given the same organizational context and similar prior experiences and skill sets, individuals nevertheless differ in how much ambiguity and uncertainty they allow to enter into their problem-solving processes.

\section{EFFICIENCY AND OUTCOMES OF PROBLEM SOLVING}

So far we have argued that a problem is not characterized by inherent levels of uncertainty and ambiguity, but that the problem solver chooses the uncertainty 
and ambiguity levels in the problem-framing process. This choice, we have proposed, is embedded in a situational context. In this section we suggest that the fit between the situational context and the choice of uncertainty and ambiguity levels has predictable consequences for the efficiency and nature of outcomes of the process. This results from uncertainty and ambiguity reduction being different processes and thus placing different requirements on the organizational context and on the necessary resources.

\section{Efficiency}

Problem solving under uncertainty is characterized by the availability of mental models considered adequate to the problem. These mental models specify the relevant variables and their functional relationships. Problem solving consists of gathering and integrating information required by the models. In other words, the models determine which information is needed and how to integrate it.

Consequently, the problem-solving process can be specified a priori. The problem-solving task can be decomposed into well defined subtasks, using such rules as minimizing interdependence between separate tasks (Hippel 1990). Smith and Eppinger (1991) demonstrate that the Design Structure Matrix can be used to structure a well-understood design task consisting of several interdependent subtasks so that an optimal task partitioning and ordering can be determined ex ante. In other words, the efficiency of the problem-solving process can be increased by a content-specific organization of tasks. Content-specific means that the tasks to be accomplished are described, complete with specifications for the tangible results desired and the inputs needed. In our earlier illustration of the improvement of a semiconductor production process, for example, in case two (uncertainty reduction), the manager would be able to specify a program wherein photoresist quality, chip complexity and operator skill would be systematically measured and used within his model to improve his prediction of weekly output.

Since the tasks are definable in situations of uncertainty, it is possible to describe precisely the content of specific roles that need to be fulfilled in order to complete the problem-solving task. Job descriptions that define the content of tasks associated with the job are possible. In the illustration above, the manager knows precisely what to measure, and can construct a detailed project plan and assign welldefined tasks to his staff and specify expected outputs. Similarly, communication networks can be structured that support the problem-solving process. Project boundaries can be defined and interfaces specified. Consequently, it is possible to control the content of the problem-solving process using measures that can be defined before the actual problem solving commences. In short, the problem-solving process can be structured and controlled by employing well established approaches such as described in Frank (1971) and in Newman (1973). An appropriate organizational structure for this kind of activity will tend to show the characteristics of a mechanistic organization as described by Burns and Stalker (1966). It is interesting to note that this holds true even if the variance of future states of the world is high (i.e. low predictability in a statistical sense) as long as there is clarity about the information needed and how to use the information. 
Proposition 4.1 a: Uncertainty reduction is best supported by content-specific structure and control measures.

This situation differs strongly from problem solving under ambiguity. Problem solving under ambiguity involves the construction and validation of models. The individual tasks are not known a priori, although the process for finding a solution (such as the basic scientific method) may be well understood (Simon 1978; Simon 1979). Consequently, only the process and not the content of the problem-solving task can be managed. The inability to define the problem-solving content becomes apparent when one investigates the task definitions of projects that are seen as involving a high degree of ambiguity. Typical task descriptions are "understand market needs", "define desirable product characteristics", "develop a conceptual design", and "design and test prototype". These descriptions, although meaningful, do not allow identification of the content of what is being developed. They refer to the process and not to the substance of the task.

Because ambiguity implies that it is still unclear what the content of the problem-solving tasks will be, roles can be described in general terms only. Roberts and Fusfeld (1981), for example, define the roles needed for new-product development projects as idea generating, championing, project leading, gatekeeping, and sponsoring. Again, these roles refer to the problem-solving process and not to the problem-solving content. Tight managerial control of the problem-solving process in regard to content issues is not possible. Only the process by which the problem solver searches for an answer to the problem and the functionality of the outcome (i.e. market success) can be planned and measured. Management tasks will be primarily to facilitate both communication and creativity while providing an overall context to assure that solutions are compatible with organization goals (McDonough and Leifer 1986). In sum, a common characteristic of the abovedescribed measures for managing this type of problem-solving activity is that they are to an important degree independent of the problem-solving content. We consequently characterize them as content-independent, and offer the following proposition:

Proposition 4.1b: Ambiguity reduction is best supported by contentindependent structure and control measures.

In sum, organizational characteristics and measures that best support uncertainty reduction are different from those which best support ambiguity reduction. An environment that is conducive to uncertainty reduction is not necessarily suitable for a process geared for ambiguity reduction, and vice versa. This implies that either the problem framing should be matched to the organizational environment or the organizational environment adjusted to the type of problem framing desired. Without such an adjustment an inefficient problem-solving process is likely to result.

In addition to the fit between organizational context and problem framing, the resources available for the problem-solving process need to be compatible with the way the problem is framed. To frame a problem as calling for uncertainty 
reduction implies that resources will be needed that are probably similar to the ones that have been used for previous problem-solving activities. These previous experiences are frequently at the root of solving a problem along well established paths (i.e. of reducing uncertainty) rather than of trying to find new paths (i.e. ambiguity reduction).

Proposition 4.2 a: For an uncertainty-reduction process to be efficient, the problem solver will need resources of a type that tends to be already available in the organization.

Consequently, the resources needed will either tend to be available within the organization or they can be obtained relatively easily using existing acquisition channels and skills to access them.

On the other hand, if the problem is framed to include ambiguity, resources may be needed that have not been employed in the past. For example, the problem solver might want to see whether a chemical process can achieve what has previously been accomplished mechanically. Consequently, chemical skills would be needed in addition to the mechanical skills that have been brought to bear in the past. To supply the problem solver with resources and capabilities that are outside the organization's previous experience may pose a challenge. New access channels and skills for evaluating the properties of such resources and for acquiring them might be required.

Proposition 4.2 b: For an ambiguity-reduction process to be efficient, the problem solver will need resources of a type that tends not yet to be available in the organization.

If the resources available to the problem solver and the organizational context do not match the way the problem is framed, the problem-solving process is likely to be inefficient. If ambiguity is created that cannot be reduced, confusion and frustration may result. Similarly, if uncertainty is generated without the problem solver having available sufficient resources to provide the possibility to reduce this uncertainty, costs will be incurred due to the prolongation of the problem-solving process. Thus, the fit between resources, organizational context and the chosen levels of uncertainty and ambiguity is a prerequisite for efficient problem solving.

\section{Outcome Characteristics}

Problem framing not only has consequences for the efficiency of the subsequent problem-solving process, but also strongly influences the characteristics of the problem-solving outcome. Recent detailed studies on technological change demonstrate how radical and architectural innovation require new approaches towards solving apparently similar problems (i.e. Henderson and Clark 1990). If the problem framing allows only for uncertainty and not for ambiguity reduction, then 
the problem-solving outcome will be similar to outcomes of past processes. Similarly, framing a problem as ambiguous will increase the likelihood of generating fundamentally different solutions.

Proposition 5 a: Problem framing that allows only uncertainty results primarily in problem-solving outcomes that are similar in type to past problem-solving outcomes.

Proposition 5 b: Problem framing that allows ambiguity may result in outcomes that are dissimilar in type to past outcomes.

In summary, this section has argued that the levels of uncertainty and ambiguity chosen in the framing stage of the problem-solving process have important consequences for subsequent problem-solving activity. To the extent that appropriate resources are provided, the process will be more efficient. The likelihood that those resources or the appropriate channels and skills for acquiring them will already be available in the organization is greater when the levels of ambiguity included in the problem framing are low. On the other hand, the nature of the problem solving outcome will more likely differ significantly from past outcomes if the framing of the problem includes higher levels of ambiguity.

\section{CONCLUSION}

This paper has argued, first, that uncertainty and ambiguity are dissimilar concepts. Second, it has been proposed that problems are not characterized by inherent levels of uncertainty and ambiguity, but that problem solvers choose these levels in the problem-framing process. Finally, it was argued that this choice is context-contingent and that the fit between context and the choice of levels of uncertainty and ambiguity has consequences for both the efficiency of the problemsolving process and for the characteristics of the problem-solving outcome. These relationships are summarized in Figure 2. In the figure, the relationships P1, P2 and P3, representing propositions 1,2 and 3 , refer to the contingency perspective, while relationships P4 and P5 relate to the efficiency of problem-solving and the characteristics of the outcome.

The choice of the uncertainty and ambiguity levels is an important step in finding a solution to a technical problem. This choice will affect the potential solution space, the resources needed, and the appropriate organizational context. In spite of wide-ranging and important consequences, this choice is often made implicitly, based on problem solvers' mental models of reality stemming from their personal preferences, educational background and experience, superimposed upon the capabilities, policies and needs of their organizations. 
FIGURE 2

\section{Contingency and Efficiency Perspective on the Choice of Uncertainty and Ambiguity Levels}

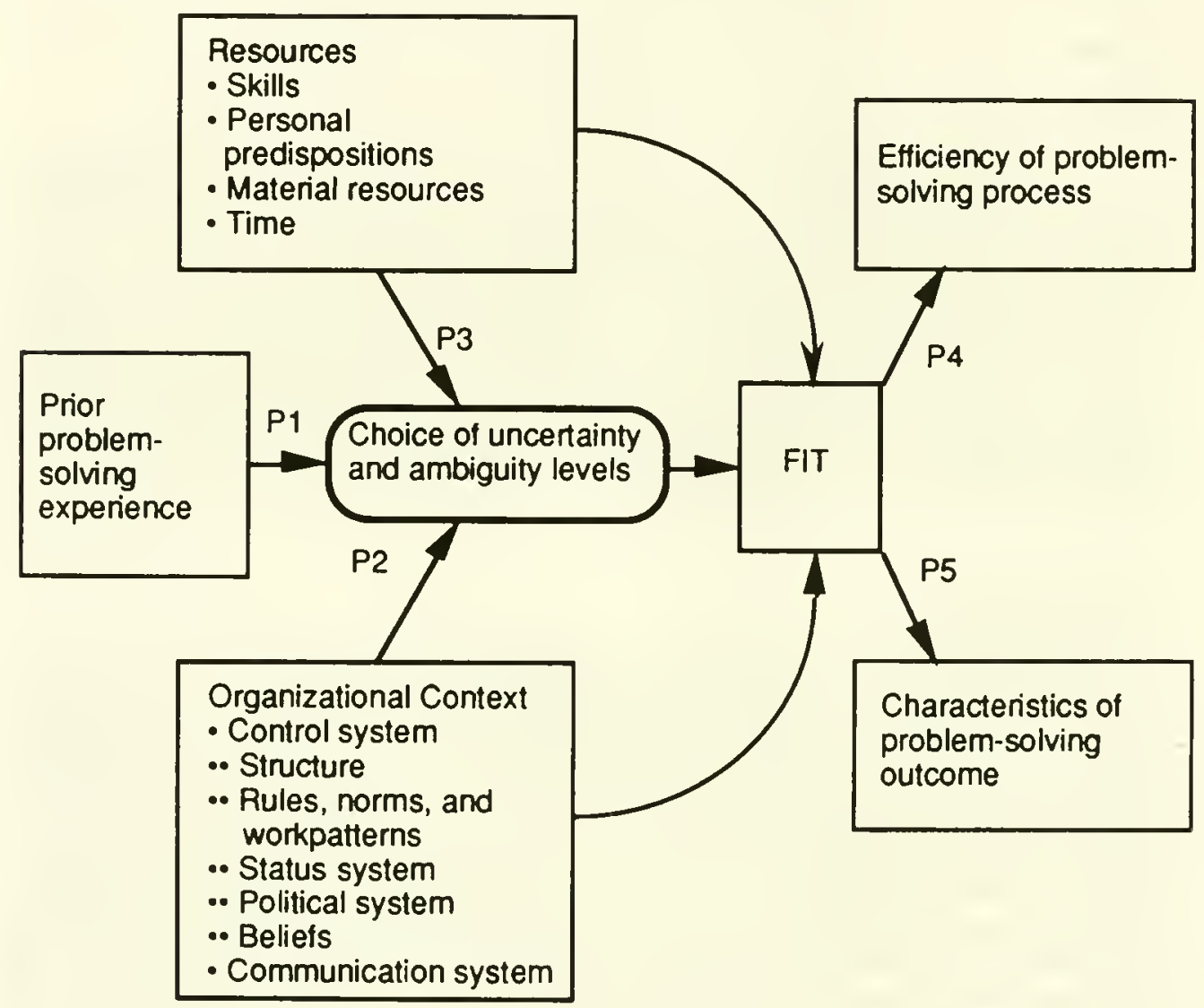

Research on the management of technology and innovation has widely neglected the problem-framing process. No attention has been paid to the choice of the uncertainty and ambiguity levels. Research has investigated the notion that the problem-solving process and its structure is contingent on the degree of uncertainty and ambiguity involved (e.g. Tushman 1978; Larson and Gobeli 1988). This research has failed, however, to distinguish clearly between uncertainty and ambiguity and to conceptualize that the relevant levels of uncertainty and ambiguity are endogenously determined. In most cases, externally ordained criteria for measurement of the degree of uncertainty or ambiguity in a given problem-solving situation have been employed. These measures might not coincide with the way the problem solvers 
themselves frame the problem, i.e. how they determine the levels of uncertainty and ambiguity. In other cases, ambiguity or uncertainty are measured by the perceptions of mangers who are located at a different organizational level than those whose problem-solving behavior is studied, again creating the possibility to misjudge the degree of uncertainty or ambiguity as determined by the problem solvers.

The framework suggested in this paper is of relevance to all those issues addressed by research on the management of technology and innovation that are related to problem solving. Two distinct research streams, research on the gatekeeper function in technology transfer and research on the role of top management in technological change exemplify how the proposed framework impacts our understanding of technology management.

Research on the transfer of technical information has demonstrated that gatekeepers can play an important role in the technology acquisition and dissemination process (e.g. Allen 1984; Tushman 1978). It did not, however, consider how gatekeepers frame problems and how their problem framing is influenced by contingency factors. Using the proposed framework, it can be speculated that gatekeepers could react in one of two generic ways when addressing technical problems. They can frame the problem as one of uncertainty reduction or as one of ambiguity reduction. This difference in framing has considerable consequences for the type of information they will seek, for the appropriateness of different communication channels, and for the resources needed for the uncertainty or ambiguity reduction process. It also has implications for how the gatekeepers should communicate their gained knowledge back into the organization. Uncertainty reduction primarily requires a translation and transfer of information whereas ambiguity reduction requires in addition a translation and transfer of frameworks. Dependent on how gatekeepers frame problems, their impact on the technical progress in their organizations will be vastly different. If they tend to frame problems as uncertain, their activities will build upon and help to improve existing technologies and skills; if as ambiguous, their activities may potentially constitute challenges to current approaches.

As suggested by the framework proposed, the personal predisposition of gatekeepers will influence whether they perceive problems as ambiguous and/or uncertain. But their choice over ambiguity and uncertainty will also depend on the organizational setting and the resources available. This would imply that organizations can influence how gatekeepers frame problems and thus how they fulfill their gatekeeper function through the design of the organizational setting and the resource mix available to gatekeepers. In other words, the ambiguity-uncertainty framework can help to identify ways to manage the gatekeeper function.

Study of the role of top managers in technological change provides the second line of research to briefly demonstrate the usefulness of the framework suggested. Two roles are frequently attributed to top management: to provide direction and to provide the infrastructure for change (e.g. Donaldson and Lorsch 1983; Gioia and Chittipeddi 1991; Virany, Tushman and Romanelli, 1992). Several researchers have suggested that top managers do not fulfill these roles unconstrained (e.g. Hambrick and Mason 1984; Miller and Toulouse 1986; Harhoff and Schrader 1992). Rather, their decision making is supposedly shaped by personal experiences, personality characteristics, and the organizational environment. However, this research has not yet systematically investigated the way in which these constructs 
affect top-management decision making. The proposed ambiguity-uncertainty framework suggests that the contingency variables discussed affect systematically the degree to which top managers are inclined to frame ambiguity and uncertainty into their problem understanding. This observation has consequences for the selection of top managers and for structuring their decision-making environment. In addition, the framework suggests that the likelihood of success of different framing choices can be predicted, using the notion that the choice needs to fit resources and organizational context. Two avenues are available to reach such a fit: Either adjusting the choice of ambiguity and uncertainty to the environment or adjusting the environment to the choice. The framework, however, also indicates that these avenues lead to different outcomes. The first alternative will favor problem solutions that are related to past solutions, whereas the second one will favor outcomes that are potentially a break with the past. In addition, the framework implies that top management can consciously manage problem-framing by their subordinates through shaping the relevant organizational context and resource mix available.

In general, the proposed framework suggests that research on the management of technology would benefit from studying the cognitive processes, especially the problem framing processes, involved in technical problem solving. Recent work (Gash and Orlikowski 1991; Orlikowski 1991; Dougherty 1992) indicates that such research might require a more involved, case-study oriented methodology than is typical of the mainstream research on the management of technology. The richness of the problem appears to require a detail-oriented approach, at least until relevant concepts are better understood.

Research based on the notion that problem solvers have a choice over ambiguity and uncertainty promises to greatly enrich our understanding of core problems faced in the management of technology and innovation. Past research in this field, however, has overlooked the issue of choosing uncertainty and ambiguity. Problem-solving processes have been studied intensively without paying attention to problem framing. Past research has been characterized by the tendency to see a problem and its fundamental structure as given. However, problems and their levels of uncertainty and ambiguity are not given, but chosen. 


\section{REFERENCES}

Allen, T. J., 1966. Studies of the problem-solving process in engineering design. IEEE Transactions on Engineering Management, EM-13: 72-82.

Allen, T.J. and Hauptman, O., 1987. The influence of communication technologies on organizational structure. Communication Research, 14(55): 575-587.

Allen, T.J., 1984. Managing the flow of technology: Technology transfer and the dissemination of technological information within the R\&D organization. Cambridge, Mass.: MIT Press.

Allen, T.J., 1986. Organizational structure, information technology, and R\&D productivity. IEEE Transactions on Engineering Management, EM-33(4): 212-217.

Anderson, P. and Tushman M.L., 1990. Technological discontinuities and dominant designs: A cyclical model of technological change. Administrative Science Quarterly, 35(4): 633.

Bougon, M., Weick, K. and Binkhorst, D., 1977. Cognition in organizations: An analysis of the Utrecht Jazz Orchestra. Administrative Science Quarterly, 22: 606-639.

Brief, A.P. and Downey H.K., 1983. Cognitive and organizational structures: A conceptual analysis of implicit organizing theories. Human Relations 36(12): 1065-1089.

Burns, T. and Stalker G.M., 1966. The management of innovation. London: Tavistock.

Clement, J., 1989. Learning via model construction and criticism: Protocol evidence on sources of creativity in science. In J. A. Glover, R. R. Ronning, and C. R. Reynolds (Eds.), Handbook of Creativity: 341-381. New York: Plenum Press.

Conrath, D.W., 1967. Organizational decision making behavior under varying conditions of uncertainty. Management Science 13(8): B487-B500.

Daft, R.L. and Lengel R.H., 1986. Organizational information requirements, media richness and structural design. Management Science 32(5): 554-571.

Daft, R.L. and Weick K.E., 1984. Toward a model of organizations as interpretation systems. Academy of Management Review 9(2): 284-295.

Donaldson, G. and Lorsch, J.W., 1983. Decision making at the top: The shaping of strategic direction. Basic Books, New York.

Dougherty, D., 1992. Interpretive barriers to successful product innovation in large firms. Organization Science 3: 179-202.

Duncan, R.B., 1972. Characteristics of organizational environments and perceived environmental uncertainty. Administrative Science Quarterly 17: 313-327.

Einhorn, H.J. and Hogarth R.M., 1986. Decision making under ambiguity. Journal of Business 59(4): S225-S250. 
Fox, F.V. and Staw B.M., 1979. The trapped administrator: Effects of job insecurity and policy resistance upon commitment to a course of action. Administrative Science Quarterly, 24: 449-471.

Foxall, G.R. and Payne, A.F., 1989. Adopters and innovators in organizations: A cross cultural study of the cognitive styles of managerial functions and subfunctions. Human Relations 42: 639-649.

Frank, H.E., 1971. Organization structuring. New York: McGraw-Hill.

Galbraith, J.R., 1973. Designing Complex Organizations. Reading, Mass.: AddisonWesley.

Garner, W.R., 1962. Uncertainty and Structure as Psychological Concepts. New York: Wiley.

Gash, D.C. and Orlikowski W.J., 1991. Changing frames: Towards an understanding of information technology and organizational change. Alfred P. Sloan School of Management, Massachusetts Institute of Technology, Cambridge, Mass. Working Paper \#3320-91-MSA

Giddens, A., 1984. The constitution of society: Outline of the theory of structure. Berkeley, CA, University of California Press.

Gimpl, M.L., 1986. Decision making under ambiguity: Western vs. Japanese managers. Joumal of Business Forecasting 5(2): 9-10.

Gioia, D.A. and Chittipeddi, K., 1991. Sensemaking and sensegiving in strategic change initiation. Strategic Management Joumal, 12: 433-448.

Goofman, I., 1974. Frame analysis. New York, Harper.

Hambrick, D.C. and Mason, P.A., 1984. Upper echolons: The organization as a reflection of its top managers. Academy of Management Review, 9: 193-206.

Hannan, M.T. and Freeman J., 1984. Structural inertia and organizational change. American Sociological Review 49: 149-164.

Harhoff, D. and Schrader, S., 1992. The effect of CEO education and career background on technology strategy: Statistical evidence from the United States. In C. Karlsson (Ed.), Proceedings of the International Product Development Conference on New Approaches to Development and Engineering, Brussel, 1992: 205-219. Brussel: EIASM.

Hedberg, B.L.T., 1981. How organizations leam and unlearn. In P. C. Nystrom and W. H. Starbuck (Eds.), Handbook of organizational design, Vol. 1: 3-27. Oxford University Press, New York.

Henderson, R.M. and Clark K.B., 1990. Architectural innovation: The reconfiguration of existing product technologies and the failure of established firms. Administrative Science Quarterly 34(1): 9-30.

Hippel, E.v., 1990. Task partitioning: An innovation process variable. Research Policy 19: 407-418. 
Kirton, M., 1976. Adopters and innovators: A description and measure. Joumal of Applied Psychology, 61: 622-629.

Kosnik, T.J., 1986. Flexibility seeking and delay: The effects of ambiguity of preference on selecting a short list. Harvard Business School, Boston, Working Paper.

Kuhn, T. S., 1962. The structure of scientific revolutions. University of Chicago Press, Chicago.

Larson, E.W. and Gobeli D.H., 1988. Organizing for product development projects. Journal of Product Innovation Management 5: 180-190.

Latour, B., 1987. Science in action. Harvard University Press, Cambridge, Mass.

Lawrence, P.R. and Lorsch, J.W., 1969. Organization and environment: Managing differentiation and integration. Irwin, Homewood, Ill.

Levinthal, D., 1992. Surviving Schumpeterian environments: An evolutionary perspective. , University of Pennsylvania, Wharton School, Reginald H. Jones Center, Philadelphia, Working Paper No. 92-03.

Levitt, B., and March, J.G., 1988. Organizational learning. Annual Review of Sociology, 14, 392-415.

Luce, R.D. and Raiffa H., 1957. Games and decisions. Wiley, New York.

March, J.G., 1978. Bounded rationality, ambiguity and the engineering of choice. The Bell Journal of Economics 9: 587-608.

Marples, D.L., 1961. The decisions of engineering design. IRE Transactions on Engineering Management, EM-8(2): 55-71.

Marquis, D.G. and Straight, D.M., 1965. Organizational factors in project performance. Massachusetts Institute of Technology, Sloan School of Management, Working Paper, Cambridge, Mass.

Martin, J. and Meyerson, D., 1988. Organizational cultures and the denial, channeling and acknowledgment of ambiguity. In L. R. Pondy, R. J. Boland and T. Howard (Eds.), Managing Ambiguity and Change: 93-125. Wiley, New York.

McCaskey, M.B., 1982. The executive challenge: Managing change and ambiguity. Pitman, Marshfield, Mass.

McDonough, E.F.I. and Leifer, R.P., 1986. Effective control of new product projects: The interaction of organization culture and project leadership. Journal of Product Innovation Management 3: 149-157.

Meyerson, D. and Martin, J., 1987. Culture change: An integration of three different views. Journal of Management Studies 24: 623-648.

Miller, D. and Toulouse, J.-M., 1986. Chief executive personality and corporate strategy and structure in small firms. Management Science, 32: 1389-1409. 
Miller, G.A. and Frick, F.C., 1949. Statistical behaviorists and sequences of responses. Psychological Review 56: 311-324.

Mintzberg, H., 1976. Planning on the left side and managing on the right. Harvard Business Review 54(4): 49-58.

Nelson, R.R. and Winter, S.G., 1982. An evolutionary theory of economic change. Cambridge, Mass., Harvard University Press.

Newman, D., 1973. Organization Design: An analytical approach to the structuring of organizations. Edward Amold, London.

Orlikowski, W., 1991. Elaborations and modifications in systems development: An empirical investigation of CASE tools. Massachusetts Institute of Technology, Alfred P. Sloan School of Management. Working Paper, Cambridge, Mass.

Owen, G., 1982. Game theory. Academic Press, New York.

Popper, K.R., 1968. Conjectures and refutations: The growth of scientific knowledge. Routledge and Kegan Paul, London.

Popper, K.R., 1972. The logic of scientific discovery. Hutchinson, London.

Roberts, E.B. and Fusfeld, A.R., 1981. Staffing the innovative technology-based organization. Sloan Management Review 22(3): 19-34.

Samuelson, W. and Zeckhauser, R., 1988. Status quo bias in decision making. Journal of Risk and Uncertainty. 1: 7-59.

Schon, D.A., 1967. Technology and change: The new Heraclitus. Delacorte Press, New York.

Shannon, C.E. and Weaver, W., 1949. The mathematical theory of communication. Urbana, 11l.: University of Illinois Press.

Shubik, M., 1982. Game theory in the social sciences: Concepts and solutions. MIT Press, Cambridge, Mass.

Simon, H.A., 1978. Rationality as process and as product of thought. American Economic Review 68: 1-16.

Simon, H.A., 1979. Rational decision making in business organizations. American Economic Review 69(4): 493-513.

Simon, H.A., 1987. Making management decisions: The role of intuition and emotion. Academy of Management Executive 1(1): 57-64.

Smith, R.P. and Eppinger, S.D., 1991. Identifying Controlling Features of Engineering Design Iteration. Massachusetts Institute of Technology, Sloan School of Management, Cambridge, Mass. Working Paper.

Staw, B.M., 1976. Knee-deep in the big muddy: A study of escalating commitment to a chosen course of action. Organizational Behavior and Human Performance. 16: $27-44$.

Sutherland, J.W., 1977. Administrative decision making: Extending the bounds of rationality. Van Nostrand Reinhold, New York. 
Teece, D. J., 1986. Profiting from technological innovation: Implications for integration, collaboration, licensing and public policy. Research Policy 15: 285-305.

Tushman, M.L. and Anderson, P., 1986. Technological discontinuities and organizational environments. Administrative Science Quarterly 31:439-465.

Tushman, M.L. and Nadler, D.A., 1980. Communication and technical roles in R\&D laboratories: An information processing approach. In B. V. Dean and J. L. Goldhar (Eds.), Management of research and innovation: 91-112. Amsterdam: North-Holland.

Tushman, M.L., 1978. Technical communication in R\&D laboratories: The impact of project work characteristics. Academy of Management Journal 21: 624-645.

Virany, B., Tushman, M. L. and Romanelli, E., 1992. Executive succession and organization outcomes in turbulent environments: An organizational learning approach. Organization Science 3: 72-91.

Yates, J. (1989). Control through Communication: The Rise of System in American Management. Johns Hopkins University Press, Baltimore, London. 





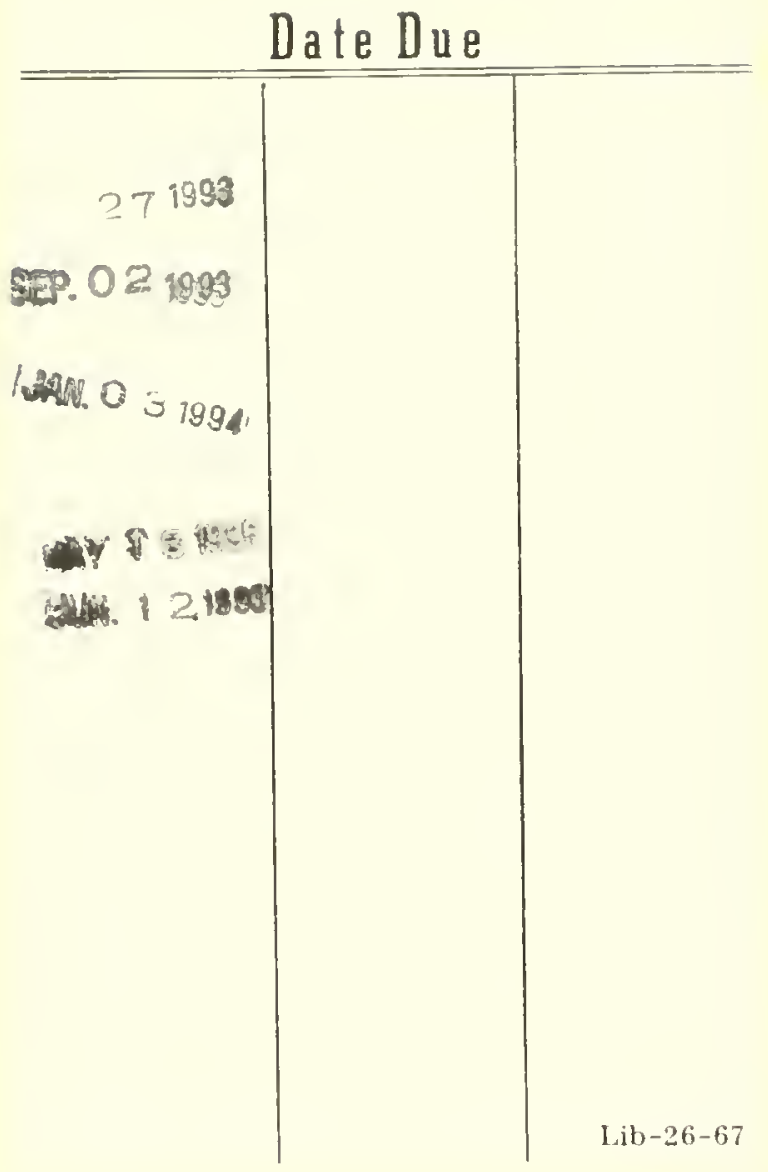




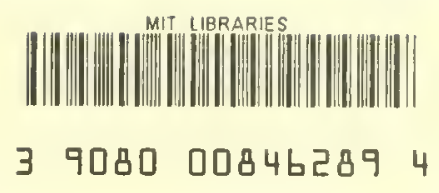


$-a+x+\cdots$ 